\title{
Situación y tareas de la teología de la liberación*
}

\author{
Gustavo Gutiérrez, \\ Lima, Perú.
}

La cuestión que me ha sido propuesta concierne al futuro de la teología de la liberación. Dos precisiones se imponen antes de entrar a hacer algunas consideraciones al respecto.

Los esfuerzos de inteligencia de la fe, que llamamos teologías, se hallan estrechamente ligados a las preguntas que vienen de la vida y de los retos que confronta la comunidad cristiana en su testimonio del reino. De este modo la teología se vincula al momento histórico y al mundo cultural en el cual surgen esas preguntas (de allí que, rigurosamente hablando, decir que una teología es "contextual" resulte tautológico, de un modo u otro toda teología lo es). Este es uno de los elementos que la definen como una función eclesial. Obviamente, en las teologías hay elementos permanentes que vienen del mensaje cristiano sobre el cual trabajan, pero su actualidad depende, en gran parte, de su capacidad para interpretar la forma como es vivida la fe, en circunstancias y en una época determinadas. La consecuencia es clara: por su lado mutable, las teologías nacen en un marco preciso, contribuyen (o deben hacerlo) a la vida de fe de los creyentes y a la tarea evangelizadora de la Iglesia, pero los acentos, las categorías. los términos y los enfoques van perdiendo su mordiente en la medida en que la situación que les dio origen no es ya la misma. Lo que decimos de la historicidad de toda teología, incluso de las de mayor envergadura a lo largo de la historia del cristianismo, vale también, obviamente, para un esfuerzo como el

- Ponencia presentada en el Coloquio Intemacional en homenaje a Gustavo Gutiérrez. organizado por la Universidad Católica de Friburgo (Suiza) en los dias 14 al 16 de abril de 1999. 
de la teología de la liberación. La teología hunde siempre sus raíces en la densidad histórica del presente de la fe'.

Esto nos lleva de la mano a la segunda anotación. Lo importante, más que preguntarse por el futuro de una teología como tal, es interrogarse por la vigencia y las consecuencias de los grandes temas de la revelación cristiana, que ella ha podido recordar y.colocar en la conciencia de los creyentes. En el caso de la inteligencia de la fe en una óptica liberadora, se trataría de puntos como el proceso de liberación - con todas las dimensiones que esto implica- de los pobres de América Latina, la presencia del evangelio y los cristianos en ese caminar y, de modo muy especial, la opción preferencial por el pobre, propuesta y esludiada en este tipo de reflexión teológica. Situaciones y temas que están en constante evolución. Esto es lo que realmente cuenta.

Tal vez una buena manera de tratar del futuro de una perspectiva teológica sca confrontarla con otras orientaciones teológicas de hoy, someter a nuevo escrutinio su propósito y sus ejes centrales, en relación con el momento presente. y echar, como consecuencia, un vistazo a las tareas que tiene por delante. En clecto, el futuro no llega, se construye; lo hacemos con nuestras manos y esperanzas, con nuestros fracasos y proyectos, con nuestra terquedad y nuesira sensibilidad a lo nuevo. Eso es lo que nos proponemos presentar esquemáticamente, en tres pasos, en las páginas que siguen.

\section{Tres grandes retos contemporáneos a la fe}

Convocando al Concilio, Juan XXIII preguntaba y se preguntaba cómo decir hoy lo que los cristianos piden cotidianamente: "que tu reino venga". Poniéndosc en camino para encontrar una respuesta a esta interrogante, recuperó un significativo tema bíblico: la necesidad de saber discernir los signos de los tiempos. Lo que quiere decir estar atentos al devenir de la historia y, más ampliamente, al mundo en el cual vivimos nuestra fe: sensibles a sus interpelaciones, impugnadoras y enriquecedoras al mismo liempo. $\mathrm{Y}$ ajenos, en consecuencia. a los temores, a las condenaciones a rajatabla y a la cerrazón de aquellos que el mismo papa llamaba "profetas de desgracias"; actitud de la cual gustan tanto quienes sc erigen a sí mismos en salvadores de los males de la época.

I. Por esa razón. a quienes, curiosamente, se preguntan si la leología de la libcración inantiene vigencia después de los acontecimientos simbolizados en al caída del muro de Berlín (un hecho, sin duda, de enorme importancia en la escena internacional). habría que recordarles que el punto de partida histórico de esa reflexión no lue la situación de los países de Europa del este. Fue, y por cierto sigue siendo, la inhumana pobreza de nuestro continente y la lectura que hacemos de ella a la luz de la fe. Estado de cosas y teología que, en cuanto a lo sustancial, poco liene que ver con el desplome del socialismo real. 
En ese orden de ideas podríamos decir, sin ninguna pretensión de exhaustividad y dejando de lado matices importantes, que la fe cristiana y el anuncio del evangelio confrontan hoy tres grandes retos: el del mundo moderno y el de la llamada posmodernidad, la pobreza de las dos terceras partes de la humanidad y el pluralismo religioso y el consiguiente diálogo interreligioso. Los tres - que hemos enumerado en orden cronológico- presentan requerimientos de gran alcance a la vida cristiana y a la tarea de la Iglesia. Al mismo tiempo, todos ellos suministran elementos y categorías que permiten emprender nuevas pistas en el entendimiento y la profundización del mensaje cristiano. Es capital tener en cuenta estos dos aspectos de una misma realidad. El trabajo teológico consistirá en mirar cara a cara esos cuestionamientos que se le presentan como signos de los tiempos y, a la vez, discernir en ellos, a la luz de la fe, el nuevo campo hermenéutico que se le ofrece para pensar la fe y para un hablar de Dios dicente a las personas de nuestro tiempo.

Al segundo de estos desafíos le consagraremos la mayor parte de estas páginas. Veamos más rápidamente el primero y el tercero.

\subsection{El mundo moderno (y posmoderno)}

Con raíces en los siglos XV y XVI, la mentalidad que se comenzará a designar como moderna impacta en la vida de las iglesias cristianas del siglo XVIII en adelante. Sus características son la afirmación del individuo como punto de partida de la actividad económica, la convivencia social y el conocimiento humano; la razón crítica que no acepta sino aquello que ha sido sometido a su examen y juicio; y el derecho a la libertad en diversos campos. Es lo que Kant llamaba el estado adulto de la humanidad. De allí la desconfianza del espíritu moderno frente a la autoridad, tanto en el plano social como en el religioso. La fe cristiana, vecina de la superstición y del sesgo autoritario - según este pensamiento-, estaría destinada a la desaparición y, en el mejor de los casos, a ser recluida al ámbito privado. La sociedad entra de este modo en un acelerado proceso de secularización y hace perder a la fe cristiana el peso social y la influencia que, en otros tiempos, tenía en las personas ${ }^{2}$. Los avatares de este conflicto, que afect6, sobre todo, a los cristianos de Europa, son conocidos; como lo son, asimismo, los pasos andados y desandados en las respuestas provocadas por los diferentes entredichos con la Iglesia. Por no hablar de los desconciertos, los temores, las audacias y los sufrimientos que se vivieron por estas razones.

2. Uno de los factores de punta de ese proceso fue, lo sabemos, el pensamiento científico. El asunto ha adquirido una nueva urgencia con el desarrollo de algunas vertientes de la ciencia, como la biogenética, por ejemplo, que plantean severas interrogantes a la visión cristiana de la vida. 
El Vaticano II, tomando distancia de quienes no veían en el mundo moderno sino un mal momento destinado a pasar y ante el cual sólo cabía resistir a pie lirme hasta que se calmara la tormenta, buscó y logró responder a muchos de estos cuestionamientos (no sin dificultades iniciales, por cierto). Hay todavía un enorme trabajo por hacer frente a la situación, es claro que, en este asunto. estamos ante una historia de larga duración?.

La tarea se ha complicado en los últimos tiempos con lo que se ha dado en llarnar por comodidad la época posmoderna ${ }^{4}$. Presentándose como una acerba crítica a la modernidad, acusada enure otras cosas de derivar fácilmente al totalitarismo (fascismo, nazismo, estalinismo), en contradicción con su fervorosa reivindicación de la libertad, y de confinarse en una visión estrecha y puramente instrumental de la razón, el talante posmoderno agudiza el individualismo. que marcaba ya al mundo moderno. Resultado de todo esto será una actitud algo desganada frente a las posibilidades de cambiar lo que antes se pensaba que no andaba bien en nuestras sociedades. Como lo es también la desconfianza de cara a las convicciones firmes en cualquier área de la acción y del conocimiento humanos, surge entonces una postura escéptica que relativiza el conocimiento de la verdad; según ella, cada quien tiene su verdad y, por ende, todo vale. Esta postura es, sin duda, uno de los motivos del desinterés por lo social y lo político al que asistimos en. nuestros días. Ella trae también, claro está, contribuciones importantes; habrá que estar atento, por ejemplo, a lo que puede significar - con todas sus ambivalencias políticas- la valoración de la diversidad cultural o élnica.

Que la posmodernidad sea un rechazo de la modernidad o su prolongación más refinada no cambia lo esencial de lo que nos interesa aquí. El conjunto constituye un gran reto para la conciencia cristiana. El tiempo ha hecho, es cierto, que surjan valiosas reflexiones teológicas que han tomado el toro por las astas. Lejos de una recusación inspirada por el miedo, no sólo han enfrentado con libertad evangélica y fidelidad al mensaje de Jesús las interpelaciones del mundo moderno y sus reverberaciones, sino que han hecho ver también todo lo que él podía aportar para revelar alcances de la le a los que no habíamos sido sensibles en el pasado o que, por una u otra razón, se habían eclipsado.

\subsection{El pluralismo religioso}

La pluralidad de religiones es, lo sabemos, un hecho milenario en la humanidad. Tanto las religiones grandes y más conocidas como las menos extendidas no son de ayer. En el pasado, su existencia planteaba algunos problemas prácti-

3. Ver al respecto la importante Historia del Concilio Vaticano $/ /$, en curso de publicación en varias lenguas, dirigida por Giuseppe Alberigo.

4. Cfr. G. Gutiérrez, "¿Dónde dormirán los pobres?”, en El rostro de Dios en la historia, Lima. Universidad Calólica. IBC. CEP.. 1996, pp. 9-69. 
cos y daba lugar a reflexiones acerca de la perspectiva salvifica del cometido misionero de las iglesias cristianas, pero en las últimas décadas, su presencia se ha convertido en una interrogante de envergadura para la fe cristiana. Todos los estudiosos del tema están de acuerdo en decir que la teologla de las religiones es muy reciente. Avanza por un terreno lleno de dificultades. Asistimos hoy en la Iglesia a un gran debate al respecto. La cuestión es sin duda delicada, importantes textos del magisterio y estudios teológicos de gran aliento han sido escritos al respecto". Como en el caso del mundo moderno, pero por razones diversas, la existencia de algunos miles de millones de seres humanos, que encuentran en esas religiones su relación con Dios, o a un Absoluto, o un profundo sentido para sus vidas, cuestiona la teología cristiana en puntos centrales de ella. A la vez, como sucede con la modernidad, le proporciona elementos y posibilidades para volver sobre ella misma y someter a un nuevo examen la significación y los alcances de la salvación en Jesucristo, en la aclualidad.

Es un territorio nuevo y exigente 6 . En él, la tentación de replegarse y de aferrarse a opciones que se consideran seguras es muy grande. Por eso son particularmente bienvenidos gestos audaces como los de Juan Pablo II, convocando hace unos años a un encuentro en Asís a los representantes de grandes religiones de la humanidad para orar por la paz en el mundo. En efecto, una teología de las religiones no puede hacerse sin una práctica de diálogo interreligioso, diálogo que apenas está dando sus primeros pasos. La teología es siempre un acto segundo. Muchos están empeñados en este esfuerzo y aquí también, y cón mayor urgencia quizá que en el desaffo anterior, hay un enorme trabajo por hacer.

La mentalidad moderna es fruto de cambios importantes en el campo del conocimiento humano y en la vida social, ocurridos fundamentalmente en Europa occidental, cuando ésta había iniciado ya su camino a un nivel de vida que la distanciará del resto de los países del planeta. En cambio, los portadores de la interpelación que viene del pluralismo religioso se encuentran entre las naciones más pobres de la humanidad. Tal vez ésta sea una de las razones que ha hecho, como lo hemos recordado, que la loma de conciencia de las preguntas que vienen de ellas se haya presentado sólo en una época reciente en las iglesias cristianas, precisamente, en el momento en que esos pueblos comenzaban a hacer oír su voz, en diferentes áreas de la convivencia internacional. Esto hace que la respuesta a las interrogantes presentadas desde Asia sobre todo, pero también de Africa y en menor escala desde América Latina, no puede separar lo

5. Véase, por ejemplo, J. Dupuis, Vers une theoligie chrêtienne du pluralisme religieux. París, Cerf, 1997.

6. Para una breve presentación de conjunto, se puede consultar M. Fédou. Les religions selon la foi chrétienne, París. Cerf, 1996. 
religioso de la situación de pobreza. Doble aspeclo cargado de consecuencias para el discurso sobre la fe, que vicne de esas latitudes.

Esta última observación nos Ileva a ahondar el reto de la pobreza que habíamos reservado para desarrollarlo en la segunda parte y que. por razones obvias. nos inleresa parlicularmente.

\section{Una pobreza inhumana y antievangélica}

Las interpelaciones a la fe cristiana que vienen del pluralismo rcligioso y de la pobreza nacen fuera del mundo noratlántico. Quienes las llevan sobre sus espaidas son los pueblos pobres de la humanidad, lo acabamos de decir a propósilo de las religiones y es el caso evidentemente de la pobreza. Este último cuestionamiento se planteó con fuerza a la reflexión teológica inicialmente en América Latina. un continente habitado por una población pobre y creyente simultáneamente, como decimos desde hace décadas, en el marco de la tcología de la liberación. Se trata de quienes viven su fe en medio de la pobreza, lo cual Irae como consecuencia que cada una de esas condiciones deje su huella en la olra: vivir y pensar la fe cristiana es algo, por lo tanto. que no pucde realizarse luera de la conciencia de la situación de despojo y marginación en que dichas personas se encuentran.

\subsection{Releer el mensaje}

Las conferencias episcopales latinoamericanas de Mcdellín (1968) y Puebla (1979) denunciaron la pobreza existente en el continente como "inhumana" y "antievangélica". Pero sabemos que, desgraciadamente, se trata de una realidad de extensión universal. Poco a poco, los pobres del mundo fueron tomando una conciencia cada vez más clara de su situación. Una serie de acontecimientos históricos en los años cincuenta y sesenta (descolonización, nuevas naciones. movimientos populares, un mejor conocimiento de las causas de la pobreza. ctc.) hicieron presentes, a lo largo y ancho del planeta, a quienes siempre habian cstado ausentes de la historia de la humanidad, o, para ser más exactos, invisihles para una manera de hacer la historia en la cual un sector de ella, el mundo occidental, aparecía como ganador en todos los campos. Es el hecho histórico que se ha llamado "la irrupción del pobre". No es por cierto un acontecimiento terıninado, se halla en pleno proceso y sigue planteando nuevas y pertinentes preguntas. En América Latina y el Caribe, cste acontecimiento fue, y es, particularmente significativo para la reflexión teológica.

La pobreza es, como el pluralismo religioso de la humanidad, un estado de cosas que viene de muy atrás. En el pasado, ella dio lugar, sin duda, a gestos admirables de servicio a los pobres y abandonados. Pero hoy, el conocimiento de su abrumadora amplitud, la brecha cada vez mayor y profunda entre los 
Lstratos ricos y los pobres en la sociedad actual y el modo que tenemos de accicarnos a clla han hecho que sólo en la segunda mitad del siglo $\mathrm{XX}$ haya comenzado a ser percibida realmente como un reto para nuestra comprensión de la le. Aunque no del todo, porque no faltan aquellos para quienes tercamente la pobreza se limita a ser un problema de orden social y económico. No es éste el sentida bíblico de esa condición, ni lo fue la intuición de Juan XXIII cuando, en vísperas del concilio, situaba a la Iglesia ante la pobreza del mundo ("los países sub(lesarrollados") y alimaba que ella debía ser "la Iglesia de lodos y especialmente la lglesia de los pobres". Sugería asi un exigente modo de concebir la Iglesia y su tarea en el mundo.

El mensaje del papa Juan lue escuchado y prolundizado ulteriormente en Aınérica Latina y cl Caribe; su condición de continente pobre y al mismo tiempo cristiano, mencionada más arriba, lo hacía particularmente sensible a la hondura teológica de la interpelación procedente de la pobreza. Una perspectiva quc. en circunstancias diferentes, habian iniciado en estas lierras, en el siglo XVI, liguras como Bartolomé de Las Casas y el indio peruano Guamán Poma, en su Jelensa de las poblaciones indígenas del continente, pero que aún hoy está lejos de ser comprendida por todos. De allí las dificultades que todavía encontramos para hacer ver el significado de las afirmaciones básicas de la leología de la liberación y de la conlerencia episcopal de Medellín, que inciden precisamentc, y teniendo en cuenta el entramado actual, en ese enfoque.

A pesar de esto. la lglesia de América Latina y del Caribe, y pronto las de otros continentes pobres, hizo ver hasta dónde llegan las demandas que vienen de la situación de pobreza y marginación de tantos seres humanos. El asunto se abre paso todavía en medio de algunos obstáculos para ser considerado en toda su hondura: un problema de vida cristiana y de reflexión teológica. Esto ocurre menos, es importante anotarlo, con el desafío -que en nuestros días llega cronológicamente después del de la pobreza a la conciencia teológica de la Iglesia- que procede del papel de las religiones de la humanidad, en el plan salvílico del Dios de la revclación cristiana. En el caso del pluralismo religioso. aunque no falten los recalcitrantes, el carácter teologico es percibido, se entien(le, Inás rápidamente. Subrayar el carácter teológico de las preguntas que acarrea la pobreza humana no significa, de ningún modo, soslayar que ella y la injusticia social tienen una inevitable y constitutiva dimensión socio-económica. Es evidente que así es. Pero la atención que debe prestárseles no viene únicamente de una preocupación por los problemas sociales y políticos. La pobreza, tal como la conocemos hoy, lanza un cuestionamiento radical y englobante a la conciencia humana y a la manera de percibir la fe cristiana. Ella conforma un campo hermenéutico que nos conduce a una relectura del mensaje bíblico y del camino a emprender como discípulos de Jesús. Esto es algo que debe ser recalcado, si queremos entender el sentido de una teología como la de la liberación. 


\subsection{Un eje de vida cristiana}

Lo que llevamos dicho se enuncia de modo claro en la conocida expresión de "opción preferencial por los pobres". La frase surgió en las comunidades cristianas y en las reflexiones teológicas de América Latina, en el período que va de Medellín a Puebla, y esta última conferencia la recogí y la hizo conocer generosamente. Sus raíces se hallan en las experiencias de la solidaridad con los pobres y en la consiguiente comprensión del sentido de la pobreza en la Biblia, que se abrieron paso en los primeros años de la década de 1960 y que se expresó ya -en cuanto a lo esencial- en Medellín. Ella se encuentra hoy muy presente en el magisterio de Juan Pablo II y en el de diversos episcopados de la Iglesia universal, así como en textos de varias confesiones cristianas. La opción preferencial por el pobre es un eje fundamental en el anuncio del evangelio que, usando la conocida metáfora bíblica, llamamos comúnmente tarea pastoral; lo es también en el terreno de la espiritualidad, es decir, en el caminar tras los pasos de Jesús. Y, por lo tanto, es asimismo un eje en cuanto a la inteligencia de la fe, que se hace a partir de esas dos dimensiones de la vida cristiana. El conjunto. esa triple dimensión, es el que le da fuerza y alcance.

Acabamos de evocar la pequeña historia de una percepción que se manifiesta en la fómula recordada; no obstante, es claro que ella, en el fondo, apunta a ayudarnos a ver cómo en este tiempo enfocamos un dato capital de la revelación bíblica que, de una manera u otra, siempre ha estado presente en el universo cristiano: el amor de Dios por toda persona y particularmente por los más abandonados. Pero ocurre que hoy estamos en condiciones de advertir con toda la claridad deseada que la pobreza, la injusticia y la marginación de personas y grupos humanos no son hechos fatales, tienen causas humanas y sociales.

Además, nos encontramos sobrecogidos por la inmensidad de esa realidad, así como por el crecimiento de las distancias, desde estos puntos de vista, entre las naciones en el mundo y entre las personas en el interior de cada país. Esto cambia el enfoque sobre la pobreza y nos empuja a examinar bajo una nueva luz las responsabilidades personales y sociales. Nos da, de este modo, nuevas perspectivas para saber descubrir continuamente el rostro del Señor en el de otras personas, en particular de los pobres y maltratados. Y nos permite ir en forma directa a lo que teológicamenté hablando es decisivo: colocarse en el corazón del anuncio del reino, expresión del amor gratuito del Dios de Jesucristo.

La comprensión que se manifiesta en la fórmula "opción preferencial por el pobre" es lo más sustantivo del aporte de América Latina a la vida de la Iglesia y de la teología de la liberación a la Iglesia universal. La pregunta planteada al comienzo de estas páginas sobre el futuro de esta reflexión debe tener en cuenta su relación factual y contemporánea con todo lo que dicha opción significa. Dicha perspectiva no es evidentemente algo exclusivo de esta teología; la exigencia y el significado del gesto hacia el pobre en la acogida del don del reino 
lorman parte del mensaje cristiano. Se trata de un discurso sobre la le, que nos permite simplemente un recuerdo y una lectura en las condiciones actuales. con toda la novedad que ellas nos revelan, de algo que, de una u otra forma -con insistencias, pero también con paréntesis-, encontró siempre un lugar a lo largo del caminar histórico del pueblo de Dios. Es relevante subrayarlo no para disminuir la aportación de esta teología, que tiene ligado su destino al sentido bíblico de la solidaridad con el pobre, sino para dibujar debidamente el ámbito en que ella se da, en tanto continuidad y ruptura con reflexiones anteriores. Y sobre todo con la experiencia cristiana y las rutas tomadas para dar testimonio del reino.

De igual manera que en los dos casos ya tratados, nos interesa resaltar aquí que en el desafío mismo proveniente de la pobreza se abren perspectivas que nos permiten seguir sacando "lo nuevo y lo viejo" del tesoro del mensaje cristiano. El discernimiento desde la fe debe ser lúcido al respecto. Pero para ello es necesario vencer el empecinamiento de ver en la pobreza del mundo de hoy sólo un problema social, eso sería pasar al lado de lo que este doloroso signo de los liempos puede decirnos. Todo lo cual se resume en la convicción de que es necesario ver la historia desue su reverso, vale decir, desde las víctimas de ella. La cruz de Cristo ilumina esa visión y nos hace comprenderla como el paso a la victoria definitiva de la vida en el resucitado.

\section{Tareas presentes}

Señalemos algunos espacios en los cuales se mueven ciertas tareas que tiene por delante la reflexión teológica que nos ocupa. Por cierto, habría muchas cosas más que decir y precisiones que hacer, pero no caben en estas pocas páginas. Esperamos tratarlas detenidamente en un trabajo de largo aliento, que está en preparación'.

\subsection{Complejidad del mundo del pobre}

Desde el inicio, en la teología de la liberación se han tenido presentes las diferentes dimensiones de la pobreza. Para decirlo en otros términos - como lo hace la Biblia-, se fue atento a no reducir la pobreza a su aspecto, capital por cierto, económico". Esto llevó a la afimnación de que el pobre es el "insignifi-

7. Eso no permitirá dar referencias bibliográficas sobre estos temas que, por ahora. obviamos. Ver, sin embargo, las que se encuentran en “Dónde dormirán los pobres?".

8. Ello se expresa en fórmulas que se encuentran desde los primeros escritos de esta teología. En referencia al pobre se habla en repetidas oportunidades de "pueblos, razas y clases sociales" (Teología de la liberación, Lima, CEP, 1971, p. 226, cfr. también pp. 251, 255) y de "las clases populares explotadas, las culturas oprimidas. 
cante". aquel que es considerado como un "no persona", alguien a quien no se le reconoce la plenitud de sus derechos en tanto ser humano. Personas sin peso social o individual, que cuentan poco en la sociedad y en la Iglesia. Así son vistos, o más exactamente no vistos, porque son más bien invisibles, en cuanto que excluidos, en el mundo de nuestros días. Las razones de ello son diversas: las carencias de orden económico sin duda, pero también el color de la piel, ser mujer, pertenecer a una cultura despreciada (o considerada interesante sólo por su exotismo, lo que al final viene a ser lo mismo). La pobreza es, en efecto, un asunto complejo y polifacético. Al hablar desde hace decenios de "los derechos cle los pobres" (ver, por ejemplo, Medellín, Paz, n. 22) nos referíamos a ese conjunto de dimensiones de la pobreza.

Una segunda perspecliva, presente igualmente desde los primeros pasos, fue la de ver al pobre como "el otro" de una sociedad que se construye al margen o contra sus derechos más elementales, ajena a su vida y a sus valores. De modo tal que, la historia leida desde ese otro (a partir de la mujer, por ejemplo) se convierte en otra historia. No obstante, releer la historia podría parecer un ejercicio puramente intelectual si no se comprende que ello significa también rehacerla. En ese orden de ideas, es firme el convencimiento, pese a todas las limitaciones y obstáculos que conocemos, especialmente en nuestros días, de que los pobres mismos deben asumir su destino. Al respecto, retomar la andadura de estas preocupaciones en el campo de la historia, desde cuando un hombre y teólogo como Las Casas se planteaba ver las cosas "como si fuese indio", es un rico lilón por explotar todavía. El primero en hacerlo, y con conocimiento de causa, fue el indio peruano Guamán Poma. Unicamente liberando nuestra mirada de inercias. de prejuicios, de categorías aceptadas acríticamente podremos descubrir al olro.

Por eso mismo, no basta tener conciencia de esa complejidad, es necesario profundizarla, entrar en el detalle de la diversidad y advertir su luerza intcrpeladora. Tampoco es suficiente tomar nota de la condición de otro del pohre (tal como lo hemos comprendido), ella debe, asimisıno, ser estudiada mús en detalle y considerada en toda su desafiante realidad. En ese proceso nos encontramos, gracias sobre todo a los compromisos concretos asumidos en y desde el mundo de la pobreza, marcada mayoritariamente entre nosotros, lo hemos hecho ver ya, con la vivencia - de un modo u otro- de la fe cristiana.

las razas discriminadas". "Praxis de liberación y le cristiana". en Signos de liberación, Lima, CEP, 1973. p. 65; ver también pp. 64, 90. 107. 111, 114. 125. Expresiones similares en "Revelación y anuncio de Dios en la historia". en Páginas. Lima. marzo de 1976. pp. 32. 36. 38. Se afirma igualmente que "la mujer de esos sectores es deblemente explotada, marginalizada y despreciada" (Teología desde el reverso de la historia, Lima, CEP, 1977. p. 34. n. 36. y "La fuerza histórica de los pobres". en Signos de lucha y esperanza. Lima. CEP. 1978. p. 173). 
La rellexión teológica se nutre de esta experiencia cotidiana, que lleva ya algunas décadas, y simultáneamente la enriquece.

Esta inquietud ha sido ahondada en los últimos años. Valiosos trabajos han permitido entrar de modo particularmente fecundo en algunos aspectos capitales de la complejidad mencionada. En efecto, en esa pista se encuentran hoy diferentes esfuerzos para pensar la fe a partir de la situación secular de marginación y despojo de los diversos pueblos indigenas de nuestro continente y de la población negra, incorporada violentamente a nuestra historia desde hace siglos. De variadas maneras hemos sido testigos en este tiempo del vigor y la contundencia que adquiere la voz de estos pueblos, de la riqueza cultural y humana que son susceptibles de aportar, asi como de las lacetas del mensaje cristiano que nos permiten ver descarnadamente. A esto se añade el diálogo con otras concepciones religiosas, las que pudieron sobrevivir a la destrucción de los siglos anteriores, minoritarias hoy - no obstante igualmente respetables, porque en ellas se encuentran comprometidos seres humanos-, pero que, sin prelender recrearlas artificialmente, están presentes con su acerbo cultural y religioso.

Las reflexiones teológicas que vienen de esos universos son particularmente exigentes y nuevas. Como lo son aquellas que provienen de la inhumana y, por consiguiente, inaceptable condición de la mujer en nuestra sociedad, en especial la que pertenece a los estratos sociales y étnicos que acabamos de recordar; en este terreno, asistimos igualmente a ricas y nuevas perspectivas teológicas, llevadas adelante sobre todo por mujeres, pero que nos importan y cuestionan a todos. Uno de los campos más fecundos es el de la lectura bíblica desde la condición femenina, pero, por supuesto, hay muchos otros campos que amplían también nuestro horizonte de comprensión de la fe cristiana.

No se trata, además, puede ser oportuno anotarlo, de la defensa de antiguas culturas fijadas en el tiempo o de la propuesta de proyectos arcaicos. que el devenir histórico habría superado, como algunos tienden a pensar. La cultura es creación permanente, se elabora todos los dlas. Lo vemos de muy diferentes maneras en nuestras ciudades. Ellas son un crisol de razas y culturas, en sus niveles más populares; pero, a la vez, son lugares crueles de distancias crecientes entre los diferentes sectores sociales que las habitan. Ambas cosas se viven en las ciudades de un continente en precipitada urbanización. Este universo en proceso, que en gran parte arrastra y transforma los valores de culturas tradicionales, condiciona la vivencia de la fe y el anuncio del reino; es, en consecuencia, un punto de partida histórico para una reflexión de orden teológico.

No obstante, el acento que el discurso sobre la fe asume legítimamente, de acuerdo con la vertiente del mundo del pobre que privilegia, no debe hacer perder de vista la globalidad de lo que está en cuestión en la condición de todos los pobres, ni descuidar el terreno común del cual parten y en el cual discurren nuestros lenguajes y reflexiones: el de los insignificantes, el de su liberación 
integral y el de la buena nueva de Jesús dirigida preferentemente a todos ellos. En efecto, hay que evitar, a toda costa, que la necesaria y urgente atención a los sulirimientos y esperanzas de los pobres dé lugar a búsquedas ineficaces de cotos tcológicos privados. Estos serían fuente de exclusividades y desconfianzas que, en última instancia, debilitan - puesto que se trata, en cuanto a lo esencial, de perspectivas convergentes y complementarias- el combate colidiano de los desposeídos por la vida, la justicia y por hacer respetar sus valores culturales y religiosos. También por su derecho a ser iguales, al mismo tiempo que diferentes.

La complejidad del universo del pobre y la perspectiva del otro percibidas inicialmente, como lo hemos recordado, se encuentran hoy mejor dibujadas con todas sus dificultades y su confliclividad, pero asimismo con todas sus promesas. No pretendemos colocar bajo un mismo rubro todas las corrientes teológicas que vienen de esa situación, la diversidad en este asunto es igualmente importante: pero los evidentes lazos históricos entre ellas, así como el horizonte común del complejo mundo del pobre en que se colocan, nos permiten verlas como expresiones fecundas de las tareas actuales de la reflexión teológica, desde los desheredados del continente. Se trata de canteras abiertas.

\subsection{Globalización y pobreza}

No estamos con los pobres si no estamos contra la pobreza, decía Paul Ricoeur hace muchos años. Es decir, si no recusamos la condición que abruma a una parte tan importante de la humanidad. No se trata de un rechazo meramente emocional, es necesario conocer lo que motiva la pobreza en el nivel social, económico y cultural. Esto requiere instrumentos de análisis que nos son suministrados por las ciencias humanas pero, como todo pensamiento científico, ellas trabajan con hipótesis, que permiten comprender la realidad que buscan explicar, lo que equivale a decir que están llamadas a cambios ante fenómenos nuevos. Es lo que sucede hoy ante la dominante presencia del neoliberalismo, que llega ahora aupado sobre los hombros de una economla cada vez más autónoma de la política ( $y$ antes ya de la élica), gracias al hecho que se conoce con el término un poco bárbaro de globalización.

La situación así designada viene, como es sabido, del mundo de la información, pero repercute pujante en el terreno económico y social, y en otros campos de la actividad humana. No obstante, la palabra es engañosa porque hace creer que nos orientamos hacia un mundo único, cuando en verdad, y en el momento aclual, acarrea ineluctablemente una contraparte: la exclusión de una parte de la humanidad del circuito económico y de los llamados beneficios de la civilización contemporánea. Una asimetría que se hace cada vez más pronunciada. Millones de personas son convertidas de este modo en objetos inservibles o en desechables, después de uso. Se trata de aquellos que han quedado fuera del 
ámbito del conocimiento, elemento decisivo de la economía de nuestros días y el eje más importante de acumulación de capital. Conviene anotar que esa polarización es la consecuencia del modo como estamos viviendo hoy la globalización, ella constituye un hecho que no tiene necesariamente que tomar el curso actual de una desigualdad creciente. Y, lo sabemos, sin igualdad no hay justicia. Lo sabemos, pero el asunto adquiere en nuestros días una urgencia creciente".

El neoliberalismo económico postula un mercado sin restricciones, llamado a regularse por sus propios medios, y somete toda solidaridad social en este campo a una dura crítica, acusándola no sólo de ineficaz frente a la pobreza, sino incluso de ser una de las causas de ella. Que haya habido casos de abusos en esa materia es claro y reconocido, pero aquí estamos ante un rechazo de principio, que deja en la intemperie a los más frágiles de la sociedad. Una de las derivaciones de este pensamiento, y de las más dolorosas y agudas, es la de la deuda externa, que tiene maniatadas y agobiadas a las naciones pobres. Deuda que creció espectacularmente, entre otras razones, debido a tasas de interés manejadas por los mismos acreedores. El pedido de su condonación es uno de los puntos más concretos e interesantes de la convocación hecha por Juan Pablo I para celebrar un jubileo del año 2000 , en el sentido bíblico del término.

Esta deshumanización de la economía, comenzada un buen tiempo atrás, que tiende a convertir todo, incluso a las personas, en mercancías ha sido denunciada por una reflexión teológica que desvela el carácter idolátrico, en el sentido biblico del término, de ese hecho. Pero las circunstancias actuales no sólo han convertido en más apremianle este señalamiento, sino que, además, proporcionan nuevos elementos para profundizarlo. De otro lado, asistimos a un curioso intento de justificación teológica del neoliberalismo económico que compara, por ejemplo, las corporaciones multinacionales con el siervo de Yahvé, a quien todos atacan y vilipendian, y, sin embargo, de ellas vendrían la justicia y la salvación. Por no hablar de la llamada leología de la prosperidad, que tiene lazos muy estrechos, por cierto, con la postura que acabamos de recordar. Esto ha invitado, a veces, a postular un cierto paralelismo entre cristianismo y docirina neoliberal. Sin negar sus intuiciones, cabe preguntarse por el alcance de una operación que nos recucrda aquella que, en el extremo opuesto, se hizo años alrús para refutar al marxismo, considerado también como una especie de "religión" que además seguiría, jalón por jalón, el mensaje cristiano (pecado original y propiedad privada, necesidad de un redentor y prolelario, etc.). Pero esta observación no quita nada, claro está, a la necesidad de una crítica radical a las idcas dominantes hoy en el terreno de la economía. Todo lo contrario.

9. Cfr. las penelrantes disquisiciones al respecto de Norberto Bobbio, Destra e simistra. Ragioni e significati di una distincione politica, Roma, Donzelli. 1994. 
Una reflexión teológica a partir de los pobres, preferidos de Dios, se impone. Ella debe tomar en cuenta la autonomía propia de la disciplina económica y al mismo tiempo tener presente su relación con el conjunto de la vida de los seres humanos, lo cual supone, en primer lugar, considerar una exigencia ética. Por lo mismo, evitando entrar en el juego de las posiciones que acabamos de mencionar, no habrá que perder de vista que el rechazo más firme a las posiciones neoliberales se da a partir de los contrasentidos de una economía que olvida cínica y, a la larga, suicidamente al ser humano. En particular a los que carecen de defensas en este campo; es decir, a la mayoría de la humanidad. Se trata de una cuestión ética, en el sentido más amplio del término, que exige entrar en los inecanismos perversos que distorsionan desde dentro la actividad humana que llamamos economía. Valiosos esfuerzos de reflexión teológica sc hacen en esta línea entre nosotros.

En este renglón, el de la globalización y la pobreza, debemos colocar también las perspectivas abiertas por las corrientes ecológicas ante la destrucción. suicida igualmente, del medio ambiente. Ellas nos han hecho más sensibles a todas las dimensiones del don de la vida y nos han ayudado a ampliar el horiconte de la solidaridad social, que debe comprender un respetuoso vínculo con la naturaleza. El asunto no afecta únicamente a los países desarrollados, cuyas industrias causan tanto daño al hábital natural de la humanidad, toca a todos, también a los países más pobres. Imposible hoy en día reflexionar teológicamente sobre la pobreza sin tener en cuenta estas realidades.

\subsection{Profundización de la espiritualidad}

Si los puntos anteriores estuvieron de una manera u olra presentes o esbozados desde los primeros pasos de la teología de la liberación, sin negar. claro está, lo propio y creativo del trabajo al que hemos asistido en estos últimos años, el de la espiritualidad ocupó siempre un lugar de primer plano. Además de la importancia del asunto para todo cristiano, afll se juega la suerte del tipo de teología que postulamos. En efecto, una profunda convicción que siempre nos ha acompañado, y en la cual la obra de $M$. D. Chenu nos ayudó inmensamentc. es que detrás de toda inteligencia de la fe hay una manera de seguir a Jesús"'. La espiritualidad, asl designamos hoy lo que en los evangelios se conoce como el seguimiento de Jesucristo, es la columna verlebral del discurso sobre la fe. Ella es la que le da su significación más profunda y su alcance. Este es uno de los puntos centrales de la comprensión de la teología como una reflexión sobre la práclica, que constituye, precisamente, el corazón del discipulado. Sus dos grandes y entrelazadas dimensiones, la oración y el compromiso histórico, conforman aquello que en el evangelio de Mateo es llamado hacer "la voluntad del

10. Cfr: su célebre Une école de thélogie. Le Saulchoir. La Saulchoir. 1937. 
Padre", por oposición a un simple decir "Señor, Señor" $(7,21)$. Cobra así sentido la afirmación de que "nuestra metodología es nuestra espiritualidad"1". Ambas son caminos hacia Dios y es necesario seguir avanzando en ellos.

En tiempos recientes hemos tenido una abundante producción en la línea de una espiritualidad de la liberación. La razón es simple: la experiencia espiritual del pueblo pobre del continente, en medio de un proceso histórico que sabe de logros y tropiezos, ha crecido en madurez. Este interés no significa, en modo alguno, una posición de repliegue frente a opciones de orden social que mantcnemos en toda su vigencia, en tanto que expresión de la solidaridad con los pobres y oprimidos. Quienes así opinan parecen desconocer la radicalidad que viene de ir al fondo de las cosas, allí donde se anudan colidianamente amor a Dios y amor al prójimo. En esa hondura se sitúa la espiritualidad. Lejos de ser una evasión de los retos del presente, ella da firmeza y durabilidad a las opciones que acabamos de aludir. Tenía razón Rilke cuando decía que Dios se cncuentra en nuestras raíces. $Y$ nunca terminamos de profundizarlas.

En el núcleo mismo de la opción preferencial por el pobre hay un elemento espiritual de experiencia del amor gratuito de Dios. El rechazo a la injusticia y la opresión que ella implica está anclada en nuestra fe en el Dios de la vida. No sorprende, por eso, que esa opción haya sido rubricada por la sangre de quienes. como decía Mons. Romero, han muerto con "el signo martirial". Fuera del caso (Icl propio arzobispo de San Salvador, esa es la situación sufrida por numerosos cristianos, en un continente que se pretende cristiano también. No podemos dejar de lado esta cruel paradoja en una reflexión sobre la espiritualidad, en América Latina. En verdad, de muchas maneras la vivencia de la cruz marca la vida cotidiana de los cristianos del continente y del Perú'?

En ese orden de idcas es capital el itinerario espiritual de un pueblo que vive su lic y mantiene su esperanza, en medio de una vida cotidiana hecha de pobreza y exclusiones, pero también de proyectos y de una mayor conciencia de sus derechos. Los pobres de América Latina han emprendido la ruta de la afirmación de su dignidad humana y de su condición de hijas e hijos de Dios. En ese caminar se da un encuentro con el Señor, crucificado y resucitado. Esıar alento a esa experiencia espiritual, recoger las versiones orales y los escritos en que ella es narrada se convierte en una tarea primordial de la reflexión teológica que se hace entre nosotros. "Beber en su propio pozo", Ilamábamos a ese momento, usiundo una expresión de Bernardo de Claraval. Sus aguas nos permitirán ver la medida de la inculturación de la fe cristiana en pueblos pobres, pero poseedores de una cultura y de una andadura histórica diferentes a las que encontramos en el inundo noratlántico.

11. "La luerza histórica de los pobres". en Signos de lucha y esperamza. p. 176.

12. Ver sobre estos temas jos valiosos Irabajos de Jon Sobrino. 
Lo que acabamos de decir es una consecuencia de una comprobación ya recordada: el pueblo latinoamericano es, mayoritariamente, pobre y creyente a la vez. En el corazón de una situación que los excluye y maltrata, y de la cual buscan liberarse, los pobres creen en el Dios de la vida. Como decían, en nombre de los pobres del Perú (más de un millón de los cuales se hallaban allí presentes), nuestros amigos Víctor (hoy fallecido) e Irene Chero a Juan Pablo ll, durante su visita al país (1985): "Con el corazón rolo por el dolor, vemos que nuestras esposas gestan en la tuberculosis, nuestros niños mueren, nuestros hijos crecen débiles y sin luturo", y añadían: "pero, a pesar de todo esto, creemos en el Dios de la vida". Es un contexto, o más bien, una realidad vital, que una reflexión sobre la fe no puede eludir. Más bien, debe nutrirse de ella. Continuamente.

Unas palabras para concluir. Si bien, como es explicable, hemos puesto el acento en la interpelación que viene del mundo de la pobreza, estamos lejos de pensar que los otros dos cuestionamientos no nos afectan en América Latina y el Caribe. La reflexión teológica del mundo cristiano tiene que enfrentar los tres retos mencionados e incluso hacer ver sus relaciones mutuas. Apenas las hernos rozado en estas páginas, pero estamos convencidos de la importancia y lecundidad de establecer esa trama.

Para ello habría que evitar la tentación de encasillamiento, que consistiría en asignar dichos desafíos a los diversos continentes. El de la modernidad al mundo occidental, el de la pobreza a América Latina y Africa y el que viene del pluralismo religioso a Asia. Sería una solución de facilidad, ajena a los cruces y contactos que se dan hoy entre diferentes pueblos y culturas, así como a la rapidez de la información a la cual asistimos y que da lugar a la cercanía que expcrimentan personas distantes geográficamente.

Naturalmente, hay énfasis propios, según las diversas áreas de la humanidad. Pcro son sólo eso, acentos. En la actualidad, estamos llamados a una tarea teológica que emprenda nuevas rutas y mantenga con mano firme tanto la particularidad como la universalidad de la situación que vivimos. Ese cometido no podrá llevarse a cabo si no con una gran sensibilidad a las diversas interpelaciones recordadas y con un respetuoso y abierto diálogo que asuma como punıo de partida histórico las condiciones de vida -en todos sus niveles- de los seres humanos y de su dignidad, en particular los pobres y excluidos. Ellos son para los cristianos reveladores de la presencia del Dios de Jesucristo, en medio de nosolros.

Estamos ante una estimulante y prometedora tarea, en la cual la teología de la liberación tiene mucho por hacer. y sobre todo que aprender. 